\section{LINGUISTIC LANDSCAPE: HISTORY, TRAJECTORY AND PEDAGOGY}

\section{Thom Huebner ${ }^{1}$}

\begin{abstract}
Language as it appears in the public space, often referred to as "linguistic landscape," has been the object of serious academic study for over a decade, resulting in several singled-authored and edited volumes, numerous articles in international journals, theses, dissertations, eight international workshops on four continents and at least one dedicated web site. In Asia, studies have been conducted in Japan, China, Hong Kong, Cambodia, Malaysia, among other countries. A 515 item bibliography compiled by Chula alum Robert Troyer can be found at www.zotero.org $>$ groups $>$ linguistic landscape bibliography.
\end{abstract}

Increasingly, researchers have explored the relationship between linguistic landscape and education, both inside and outside of schools. In educational settings, studies have explored the connection between the linguistic landscape and linguistic awareness and language learning input. Other intersections of linguistic landscape and education are the dynamics of language and power and of language and identity. Yet the full potential for using linguistic landscape as a pedagogical tool have gone relatively unexplored in Thailand and throughout

1 Professor Emeritus, Department of Linguistics and Language Development, San José State University, San José, California, U.S.A.
Southeast Asia. The purpose of this paper is to begin the first steps in filling this gap. It provides a brief history of the development of the field, describes various methodologies employed and identifies some current and future research trajectories for the study of LL. It also introduces five student papers from a course taught at Chulalongkorn University in the 2015 academic year. Each paper exemplifies issues found in the public space. Together they begin a dialog about the implications of language in the public sphere in Thailand.

\section{Introduction}

Language in the public space is so ubiquitous that we often become impervious to it. Yet as an integral part of the larger physical landscape, environmental print helps to create and convey a sense of place, community, power, contestation and negotiation. Although the study of public signage predates the term "linguistic landscape" (Spolsky 2009: 26-28), it was an article by Landry and Bourhis twenty years ago that saw in language in the public space implications for the sociolinguistics of language planning and community ethnolinguistic vitality. Their paper introduced the term "linguistic landscape" to refer to the "visibility and salience of languages on public and commercial signs in a given territory" (1997:23). This paper reviews the development of linguistic landscape (LL) as a research area, plots the theoretical and methodological trajectories of LL research over the past decade, and introduces the remainder of the papers in this volume. 


\section{A Brief History (From a Personal Perspective)}

The Landry and Bourhis article inspired a number of subsequent papers using the term "linguistic landscape" which began making the conference circuit of the American Association for Applied Linguistics (Arlington Virginia 2003, Portland Oregon 2004) and the European Second Language Association (San Sebastian Spain 2004) panel presentations. Four idiosyncratic papers from these panels were first published in the International Journal of Multilingualism (Vol. 3:1, 2006) and in the same year reprinted as a monograph by Multilingual Matters (Gorter 2006). Whether or not the study of linguistic landscape represented "a new approach to multilingualism" (Gorter 2006) or simply an often neglected source of sociolinguistic data, these early papers contributed to our understanding of the symbolic construction of the public space through an examination of the use of language in multilingual signs, codeswitching and hybrid varieties. At the same time these papers, including my own, were heavily quantitative, narrowly language-focused and struggling to define geographic territory, units of analysis and relative language prominence in multilingual signs.

As the number of conference papers and panels on linguistic landscape grew, it became apparent that a conference focusing specifically on LL was both feasible and desirable. In 2008 the first "Linguistic Landscape Workshop" was convened in Tel Aviv, resulting in a second publication dedicated to LL (Shohamy and Gorter 2009). Seven subsequent linguistic landscape workshops have been held at a variety of international sites on three continents:

\author{
2009 - Siena, Italy (Siena \\ University for Foreigners) \\ 2010 - Strasbourg, France (University \\ of Strasbourg) \\ 2012 - Addis Ababa, Ethiopia (Addis \\ Ababa University) \\ 2013 - Namur, Belgium (University of \\ Namur) \\ 2014 - Cape Town, South Africa \\ (University of the Western \\ Cape) \\ 2015 - Berkeley, California, USA \\ (University of California) \\ 2016 - Liverpool, England (Liverpool \\ University)
}

As of this writing, plans are being made for Linguistic Landscape Workshop 9 scheduled for Luxembourg in the spring of 2017. Since the first workshop, LL has become the object of serious academic research, resulting in several singledauthored and edited volumes, numerous articles in international journals, including its own disciplinary journal (Linguistic Landscape: An International Journal, John Benjamins Publishing Company, Amsterdam and Philadelphia), MA theses, $\mathrm{PhD}$ dissertations, and at least one dedicated web site. (See Robert Troyer's review in this volume for a listing of some of the primary resources in the area.) One can now find papers on linguistic landscape at professional meetings and conferences in sociolinguistics, anthropology, sociology and education. A 516 item bibliography compiled by Robert Troyer devoted to LL studies can be found at www.zotero.org $>$ groups $>$ linguistic landscape bibliography.

\section{Research Trajectories}

With the development of an academic literature, the objects, methods and tools of analysis, indeed the very notion of 
linguistic landscape, have expanded to address different research objectives and to better understand the roles and impact of language in the public space. In their account of the evolution of the field, Barni and Bagna (2015: 10-11) identify three areas of development:

a. The objects and actors involved;

b. The relationship with other disciplines;

c. The choice of the most suitable methodologies for different LL research goals.

\section{Objects and Actors}

The range of objects in the linguistic landscape is no longer limited to "the language of public road signs, advertising billboards, street names, place names, commercial shop signs and public signs on governmental buildings" identified in the original Landry and Bourhis article, but rather includes such phenomena as graffiti (e.g., Pennycook 2009, 2010) and the language of tourist post cards (Jaworski 2010), of science lab bulletin board notices (Hanauer 2009), of the banners and placards at sporting events (Monaghan 2016), and of cyberspace (e.g., Ivkovic \& Lotherington 2009, Jones 2011, Troyer 2012). The objects of analysis have become not only the framed and static manifestations of the ethnolinguistic composition of a neighborhood. The creation of meaning of a given sign results not from the language alone, but rather from the symbiotic relationship between the language of public signage and other, non-linguistic semiotic modes in the public space in which the language is embedded, such as images, colors, sounds, the architecture of monuments (e.g., Shohamy and Waksman 2009, Abousnnouga and Machin 2011) and building facades (Gendelman and Aiello 2011), and the physical trajectories of participants as they move through the public space (e.g., Lou 2010, Garvin 2010).

In the earlier studies, actors, including authors, intended readers, and inhabitants of the area, were only indirectly implied. Describing the state of affairs in the early LL research, Malinowski has pointed out

$$
\begin{aligned}
& \text { "the domain of human agency behind } \\
& \text { the linguistic landscape remains } \\
& \text { unnamed, with authorial intent } \\
& \text { couched between two more visible } \\
& \text { dichotomies: (1) the semiotic reading } \\
& \text { of the dominance of one linguistic } \\
& \text { code over another on bilingual signs, } \\
& \text { and (2) the distinction between } \\
& \text { government or officially authored } \\
& \text { 'top-down' and private or individual } \\
& \text { 'bottom-up' signs." (2009: 108) }
\end{aligned}
$$

He notes that sociologists Ben-Rafael et al. (2006) offer three views of the forces behind language choice and authorship in the LL. First, they propose that the dominance of one language over another in a bilingual sign as indicated by size, type, color and placement of font is tied to the power relations between dominant and subordinate groups. Second, they assert that the LL can be seen as a vehicle for the presentation of self and as a community identity marker. Finally Ben-Rafael et al. suggest that choices apparent in the LL are also governed by the expected influence on its consumers. Malinowski addresses the issue of authorship more broadly to include all actors and forces that bring meaning to bear on any item in the LL. When viewed from the perspectives of Judith Butler's performativity theory and of multimodality, Malinowski concludes that authorship of signs is "a complex, 
dispersed entity who is only somewhat in control of the meanings that are read of his or her written 'utterance."” (2009: 108)

\section{Disciplinary and Theoretical Perspectives}

With an expanded range of objects beyond mere signs and a more carefully articulated awareness of the complexity and importance of authorship, LL research has been approached from multiple disciplinary and theoretical perspectives. The opening section of Shohamy and Gorter (2009) lays out six theoretical perspectives. In that section, Coulmas takes an archeological approach to the study of ancient inscriptions of ancient Babylon, Egypt, Persia and elsewhere, asking who wrote the inscriptions, where the inscriptions were located and what functions they served, illustrating the point that "a LL is a cultural scene, formed by interested agents whose motivations and intentions pertaining to information contents, language choice and symbolic significance, to the extent they can be inferred, must be reckoned with" in any LL analysis. (2009: 23) From a sociolinguistic perspective, Spolsky proposes three relevant conditions that determine the choice of languages in a sign: 1) "write in a language you know"; 2) "write in a language which can be read by the people you expect to read it;" and 3) "write a sign in your own language or in a language with which you wish to be identified." (2009: 33) Drawing on the works of sociologists such as Erving Goffman, Jürgen Habermas, and Pierre Bourdieu, Ben-Rafael (2009:45-46) looks at LL through four "principles of structuration": presentation of self, the good-reasons principle, collective identity and power-relations. Cenos and Gorter attempt to apply a market valuation model from environmental economics to explain the linguistic diversity found in the LL. Huebner (2009) provides a framework for the analysis of the LL based on Hymes' (1976) ethnography of communication and the SPEAKING pneumonic to explore the possible linguistic dimensions that need to be taken into account when researching the LL. Finally, Hult employs a nexus analysis framework (Scollon and Scollon 2004) to explore the language ecology of a region in southern Sweden. He concludes that "... the application of ideas from nexus analysis permits one to interpret data from a linguistic landscape in greater depth than can be extrapolated from only the quantitative distribution of languages." (2009: 101)

Other frameworks have also been applied to the study of LL. For example, Blommaert's in depth ethnographic study focusses on the Oud-Berchem area of Antwerp, a neighborhood where he has lived for about two decades. He argues that this ethnographic approach provides a diachronic lens through which one can witness the complexity of a layered "system of systems" (individual, peer group, local, national, etc.) in which "change at one level also creates effects at other levels." (2013: 12) Malinowski's (2009) study of signs on ethnic Korean businesses in Oakland, California employs a multimodal analysis. Trumper-Hecht draws on Lefebvre's triadic paradigm of conceived, perceived, and lived spaces to examine the use of Arabic in Israel's mixed cities from the perspective of those walking its streets.

\section{Methodologies and Themes}

The increasingly multdisciplinary nature of and varied theoretical approaches to LL research has entailed expanded research 
methodologies and themes. Methodologically, early studies were heavily quantitative, a feature that has sometimes been inaccurately characterized as simply counting signs and languages. Barni and Bagna explain, "studying the LL does not mean limiting oneself to counting the languages present in it, but involves contextualizing the analysis, broadening it to encompass the actors who shape or use the landscape and the factors which have contributed to its formation over time. (2015: 14) Similarly, Blackwood, in recounting the evolution of his thinking on methodological challenges during his nearly decade-long investigation of France's regional languages in the public space, recognizes the importance of a quantitative dimension to the study of LL:

"In recent years, there has been a reductivist tendency to simplify the quantitative approach as merely involving the counting of signs, whereas qualitative research is viewed more positively; it explores issues pertaining to the behavior of the social actor, using the LL as a site of inquiry. Clearly, this is a simplified description of the two methodologies, but in this section we seek to outline ways by which the quantitative approach is a prerequisite for LL research which seeks to describe and analyse a given space. ... [W] e argue that a symbiotic approach, where the quantitative and qualitative approaches feed into one another, is an ideal modus operandi. (Blackwood 2015: 39-40)

The qualitative approaches and methodologies that have emerged over the past decade involve not just interviews with sign authors, shop owners and consumers of the LL, but also participant observation, attitudinal questionnaires and surveys and historical documentation. Innovative technologies such as Global Positioning Systems, small video and audio recording devices, Google Earth and Google Maps (see Troyer, this volume) and ArcGIS, a geographic information system (Barni and Bagna 2009) have led to more efficient and exhaustive collection and analysis of data. "Walking tours" of inhabitants and passers-by capture impressions and reactions to the LL (Garvin 2010). For languages less commonly found in the LL (Marten (2016) proposes use of a method he calls "Spot German," which searches out and analyzes the presence of or reverence to German or any other language that is not a dominant language in a specific physical or virtual space.

The most appropriate methodologies, however, are determined by the research questions asked and the themes pursued. Investigations in LL document the relationship between language and, among other things, power, contestation and negotiation of rights and ownership; multilingualism and individual identity construction; language awareness and language attitudes; local language and national identity; language and religion; government language policy versus language practice; minority language suppression or maintenance or revival; tourism and the commodification of culture; etc. One area of rapidly growing research interest is the intersection of LL and education, in particular language teaching and learning. 


\section{Linguistic Landscape and Language Teaching and Learning}

The role of LL in education and specifically in language education has been discussed in both theoretical papers and in research reports of specific schoolbased LL projects. Cenose and Gorter (2008) explore the potential of LL from the perspective of language learning input, the development of literacy skills, pragmatic and literacy competence, and its symbolic function as a vehicle for addressing affective factors. Dagenais et al. (2009) documents the role of LL in the development of language awareness among elementary school students in Canada. Sayer (2010) describes how he engaged his language learners through a pilot study he conducted in Mexico. Bolton (2013) examines the causes and effects of globalization and the rise of World Englishes through the prism of English in the public space. Dressler (2015) researches the degree to which signs promote bilingualism in a Canadian bilingual school program whose goal of promoting bilingualism is seen as a natural outcome of providing language instruction in two languages. In another Canada-based project, Burwell and Lenters report on a case study "in which Grade 10 students took on the role of researchers to explore the linguistic, visual and spatial texts of their neighbourhood," (2015: 201) the result of which combined visual analysis with the production of place-based documentaries.

Perhaps the most thorough theoretical and practical articulation of the intersection of LL and language teaching and learning is Malinowski's position paper (2015a) and accompanying resource document (2015b). Drawing heavily on TrumperHecht's interpretation of Lefebvre's paradigm of conceived, perceived and lived spaces mentioned above, Malinowski identifies some practical roles and applications of LL to language pedagogy. For example, "activities in 'perceived space' orient language learners toward meanings they can physically read, see, hear, and otherwise observe from the material and social environments that surround them." (2015b: 2) This might include participant observation and documentation of the LL in the form of photographing and counting phenomena of interest such as bilingual signs, codes used and other, non-linguistic elements. Conceived space activities would "orient learners toward top-down understandings of spaces as planned, designed, legislated promulgated, and enforced" (ibid.) and include study of maps, diagrams, policy statements and demographic data. Lived space refers to "the experiential dimension of linguistic landscape as imagined, felt, and experienced by inhabitants." (ibid.) Learning activities might include interviews with property owners and longtime area residents, journals and notebooks recording learners' own selfreflection as they experience the LL, and artistic and imaginative projects such as imaginative mapping, mural design and even interpretive movement/dance.

Clearly the potential of LL as a pedagogical tool is powerful. At the linguistic level, student explorations of signs in the LL can contribute to increased awareness of lexical borrowing, syntactic patterning, and phonological adaptation and rhetorical devices like assonance, alliteration, metaphor, and personification, and can generate discussion of the purposes and effects of code switching and hybrid language. At another level, students can use the LL to explore issues of identity and ethnicity. At a macro level, students can research both overt and covert 
language policy, discrepancies between them and the meanings behind those discrepancies. In her review of several studies of LL and language policy and the effects of students as action researchers, Shohamy (2015) states, "The engagement of high school student with documentation of LL in their neighborhoods was found to have a real impact on L[anguage]P[olicy] awareness and activism." (2015:154).

\section{The Current Issue}

The growing body of literature on LL comprises studies from around the world, including Asia (e.g., Japan: Backhaus 2007, Kallen and Dhonnacha 2010, Rowland 2016; China: Wang 2013, Xia and Li 2016; Korea: Malinowski 2010; Taiwan Curtin 2009; Hong Kong: Jaworski and Yeung 2010, Lai 2013). ASEAN countries where LL studies have been conducted include Singapore (Teng 2016), Cambodia (Kasanga 2012), Malaysia (Manan 2015, Coluzzi and Kitade 2015), and Indonesia (Macalister 2012), among others. In Thailand, the ongoing Isan Culture Maintenance and Revitalization Project (ICMRP; Draper $2010,2013,2016)$ is an example of action research using, in part, the LL to (re)introduce the local dialect into the community as a part of a larger project addressing issues of identity and cultural pride in the face of language shift and ethnic discrimination. In addition to the work of the ICMRP, several unpublished studies have been conducted of the LL in up-country provinces. A study of language of the Thai "cyberspace" (Troyer 2012) was published in English Today. My own study of the LL in several Bangkok neighborhoods (Huebner 2006) introduces a number of themes that could be explored in the very dense and data-rich LL of Bangkok: language and genre variation, code switching and linguistic hybridity, language and social stratification and social roles, language and policy, power and contestation, and language and diachronic change. Yet because of the pervasiveness and diversity of the Thai LL, the full potential for research and pedagogy remains relatively unexplored. One purpose of this paper and this volume is to encourage researchers and educators to explore the range of possibilities inherent in the LL.

The five papers in this proposal are student papers from a graduate course I taught in the English as an International Language (EIL) Program at Chulalongkorn University in the 2015 academic year. Several of the enrollees were first year graduate students and most had little or no formal training in linguistics. As a course project, each student had to conduct a small study of some aspect of LL that they were familiar with and curious about. While the five short papers included here may not contain profound implications for a theory of LL or for innovative research methodologies, they do begin a dialog about the implication of language in the public sphere and the kinds of research that can be conducted at various levels of academic maturity. Each incorporates both quantitative and qualitative data. And each offers some insight into the LL of the area investigated.

Huebner (2006) describes a phenomenon he calls "hybridity," the mixing of Thai and English lexicon, syntax and orthography. In her study of the Si Yan market in Bangkok, Prapobratanakul looks into whether that kind of hybrid language is found in a very Thai neighborhood, and if so whether shop owners and customers are aware that it is a hybrid of Thai and English, and if aware of it, what if 
anything do they think of it. The study of the LL of Bangkok's Chinatown represents a collaboration between $\mathrm{Wu}$, a student from China who is not literate in Thai, and Techasan, a Thai with close associations to Chinatown, but who is not literate in Chinese. Together they investigate the LL of Chinatown as a reflection of the negotiation of identities of second and third generation Thai-Chinese there. Thongtong shifts the study of LL to Chiang Mai, where she briefly recounts the history of Nimmanhaemin Road and describes it's current state as a tourist destination. In the process, she identifies many of the linguistic and rhetorical devices found in the public signage that contribute to its more recent status. Back in Bangkok, Suthinaraphan looks at the state of multilingualism displayed in ads found on the Bangkok Transport System's SkyTrain. The ads are almost exclusively in Thai and/or English, and exhibit a variety of code switching and blending strategies. Finally, Siricharoen asks the extent to which a university's Faculty of Arts promotes multilingualism through its LL. She finds that while Thai-English bilingualism is promoted through the Faculty's LL, the other languages taught in the Faculty are all but invisible in the LL. Most often when they do appear, it is only in the form of "bilingual winks" meant to lend an air of authenticity but which carry virtually no informational weight. An alum of the EIL program and regular contributor to the literature on LL, Robert Troyer provides a detailed review of the edited volume by Robert Blackwood, Elizabeth Lansa, and Hirut Woldemariam, Negotiating and Contesting Identities in Linguistic Landscapes (Bloomsbury Publishing, 2016).

It is hoped that this humble special issue of Manuysa will encourage those who are already be doing LL research to submit their findings for publication. For those who may not have been familiar with linguistic landscape research, perhaps this volume will provide some initial orientation to the field and stimulate researchers and educators to incorporate the study of LL in their research and language teaching agendas.

\section{References}

Abousnnouga, G. and d. Machin. 2011. War monuments and the changing discourses of nation and soldiery. In A. Jaworski and C. Thurlow, eds., pp. 219-240.

Backhaus, Peter. 2007. Linguistic Landscape: A Comparative Study of Urban Multilingualism in Tokyo. Clevedon: Multilingual Matters.

Ben-Rafael, Eliezer. 2009. A sociolinguistic approach to the study of linguistic landscapes. In Shohamy \& Gorter, eds., pp. 40-54.

Blackwood, Robert. 2015. LL explorations and methodological challenges:

Analysing France's regional languages. Linguistic Landscape 1:1/2 38-53.

Blommaert, Jan. 2013. Ethnography, Superdiversity and Linguistic Landscapes: Chronicles of Complexity. Bristol, Burralo \& Toronto: Multilingual Matters.

Bolton, K. 2012. World Englishes and linguistic landscapes. World Englishes 31.1, 30-33.

Cenos, Jasone. and Durk Gorter. 2008. The linguistic landscape as an additional source of input in second 
language acquisition. IRAL 46, 267287.

and . (2009).

Language economy and linguistic landscape. In Shohamy \& Gorter, eds., pp. 55-69.

Coluzzi, Paolo and Rie Kitade. 2015. The languages of places of worship in the Kuala Lumpur area: A study on the "religious" linguistic landscape in Malaysia. Linguistic Landscape 1.3: 243-267.

Curtin, Melissa L. 2009. Languages on display: Indexical signs, identities and the linguistic landscape of Taipei. In Shohamy and Gorter, eds., pp. 221-237.

Dagenais, Diane, Daniele Moore, Cecile Sabatier, Patricia Lamarre and Francoise Armand. 2009. Linguistic landscape and language awareness. In Shohamy and Gorter, eds., pp. 253-2169.

Draper, John. 2010. Inferring ethnolinguistic vitality in a community of Northeast Thailand. Journal of Multilingual and Multicultural Development. 31:2: 135-147.

2013. The Isan Culture

Maintenance and Revitalization Projects' multilingual and signage attitude survey: Phase I. Journal of Multilingual and Multicultural Development 34.7: 617-635.

2016. The Isan Culture

Maintenance and Revitalization Projects' multilingual and signage attitude survey: Phase II. Journal of Multilingual and Multicultural Development 35.1: 1-17.

Dressler, R. 2015. Signgeist: Promoting bilingualism through the linguistic landscape of school signage. International Journal of Multilingualism 12.1, 128-145.

DuPlessis, Theodorus. 2010. Bloemfontein / Mangaung, 'City on the move': Language management and transformation of a nonrepresentative linguistic landscape. In Shohamy, Ben-Rafael \& Barni, eds., pp. 7495.

Garvin, Rebecca Todd. 2010. Responses to the linguistic landscape in Memphis, Tennessee: An urban space in transition. In Shohamy, Ben-Rafael and Barni, eds., pp. 252-273.

Gendelman, Gill and Georgia Aiello. 2011. Faces of places: Facades as global communication in post-Eastern Bloc urban renewal. In A. Jaworski and C. Thurlow, eds., pp. 241-255.

Gorter, Durk, ed. 2006. Linguistic Landscape: A New Approach to Multilingualism. Clevedon: Multilingual Matters.

Hanauer, David. 2009. Science and the Linguistic Landscape: A genre analysis of representational wall space in a microbiology laboratory. In Elana Shohamy and Durk Gorter, eds., pp. 287-301.

Hèlot, C., M. Barni, R. Janssens, \& C. Bagna, eds. 2012. Linguistic Landscapes, Multilingualism and Social Change: Diversité des Approaches. Frankfurt: Peter Lang.

Hult, Francis M. 2009. Language ecology and linguistic landscape analysis. In Shohamy \& Gorter, eds., pp.88-104.

Huebner, Thom. 2009. A framework for the linguistic analysis of linguistic 
landscapes. In Shohamy \& Gorter, eds., pp. $70-87$.

Ivkovic, D. and Lotherington, H. 2009. Multilingualism in cyberspace: Conceptualising the virtual linguistic landscape. International Journal of Multilingualism 6.1, 17-36.

Jaworski, Adam. 2010. Linguistic landscapes on postcards: Tourist mediation and the sociolinguistic communities of contact. Sociolinguistic Studies 4.3: 569-594.

Jaworski, Adam and Simone Yeung. 2010. Life in the Garden of Eden: The naming and imagery of residential Hong Kong. In Shohamy, Ben-Rafael and Barni, eds., pp. 153-181.

Jaworski, Adam and Crispin Thurlow, eds. 2011. Semiotic Landscapes: Language, Image, Space. New York \& London: Routledge.

Jones, Rodney H. 2011. Cyberspace and physical space: Attention structures in computer mediated communication. In Adam Jaworski and Crispin Thurlow, eds., pp. 151-167.

Kasanga, L. A. 2012. Mapping the linguistic landscape of a commercial neighbourhood in Central Phnom Penh. Journal of Multilingual and Multicultural development 33.6: 553567.

Kallen, Jeffrey and Ester Ní Dhonnacha. 2010. Language and interlanguage in urban Irish and Japanese linguistic landscapes. N Shohamy, Ben-Rafael and Barni, eds., 19-36.
Lai, Mee Ling. 2013. The linguistic landscape of Hong Kong after the change of sovereignty. International Journal of Multilingualism 10.3: 251272.

Landry, R. and R. Y. Bourhis. 1997. Linguistic landscape and ethnolinguistic vitality: An empirical study. Journal of Language and Social Psychology 16.1: 23-49.

Lou, Jia Jackie. 2010. Chinese on the side: The marginalization of Chinese in the linguistic and social landscapes of Chinatown, in Washington, DC. In Shohamy, Ben-Rafael \& Barni, eds., pp. 96-114.

Macalister, John. 2012. Language policies, language planning and linguistic landscapes in Timor-Leste. Language Problems and Language Planning 36.1: 25-45.

Malinowski, David. 2009. Authorship in the linguistic landscape. In Shohamy \& Gorter, eds., pp. 107-125. 2010. Showing seeing in the Korean linguistic cityscape. In Shohamy, Ben-Rafael and Barni, eds., pp. 199-215. 2015a. Opening spaces of learning in the linguistic landscape. Linguistic Landscape 1:1/2.95-113.

2015b. Opening spaces of learning in the linguistic landscape: A resource document for language learning ideas, resources, and projects in the LL. Unpublished paper, Yale Center for Language Study, New Haven. [https://docs.google.com/document/ d/1J6Zw55g5JukHe1OeLJPbfhw9k ZLkwP6_K_8aMJ1PHwQ/edit] 
Manan, S. A. 2015. Politics, economics and identity: Mapping the linguistic landscape of Kuala Lumpur, Malaysia. International Journal of Multilingualism 12.1: 31-50.

Marten, Heiko F. 2016. "Linguistic landscape" meets "Spot German": Methodological comtemplations on two complementary approaches. Paper presented at the Linguistic Landscapes 8 Workshop: Regeneration, Revitalization, Reterritorialization. University of Liverpool, April.

Monaghan, Frank. 2016. (F)anfield: Football fan banners and the reclaiming of the linguistic landscape. Paper presented at the Linguistic Landscapes Workshop 8: Regeneration, Revitalization, Reterritorialization. University of Liverpool, April 26-30.

Pavlenko, Aneta. 2010. Linguistic landscape of Kyiv, Ukraine: A diachronic study. In Shohamy, BenRafael \& Barni, eds., pp. 133-150.

Pennycook, Alistair. 2009. Linguistic landscapes and the transgressive semiotics of graffiti. In Elana Shohamy and Durk Gorter, eds., pp. 302-312. .2011. Spatial narrations:

Graffscapes and city souls. In Jaworski and Thurlow, eds., pp. 137-151.

Rowland, Luke. 2016. English in the Japanese linguistic landscape: A motive analysis. Journal of Multilingual and Multicultural Development 37.1: 40-55.

Sayer, Peter. 2009. Using the linguistic landscape as a pedagogical resource. ELT Journal 64.2, 143-154.
Scollon, Ron and S. W. Scollon. 2004. Discourses in Place: Language in the Material World. London: Routledge.

Shohamy, Elena and Durk Gorter, eds. 2009. Linguistic Landscape: Expanding the Scenery. New York \& London: Routledge.

Shohamy, Elena, Eliezer Ben-Rafael and Monica Barni, eds. 2010. Linguistic Landscape in the City. Bristol, Buffalo and Toronto: Multilingual Matters.

Shohamy, Elena and Shoshi Waksman. 2009. Linguistic landscape as an ecological arena: Modalities, meanings, negotiations, education. In Shohamy \& Gorter, eds., pp. 313-331.

Spolsky, Bernard. 2006. Prolegomena to a sociolinguistic theory of public signage. In Shohamy \& Gorter, eds., pp. 25-39.

Teng, Hoa. 2016. Linguistic landscaping in Singapore: The local linguistic ecology and the roles of English. Lund University Libraries Student Papers SPVR01 20161.

Troyer, Robert A. 2012. English in the Thai linguistic netscape. World Englishes 31.1, 93-112.

Wang, Jingjing. 2013. Linguistic landscape of Chin: A case study of shop signs in Beijing. Canada Studies in Literature and Language 6.1: 40-47.

Xi, Na and Lisheng Li. 2016. Studying languages in the linguistic landscape of Lijiang Old Town. International Journal of English Linguistics 6.2: 105117. 